\title{
Proceeding
}

Supplementary Issue: Spring Conferences of Sports Science. Costa Blanca Sports Science Week, 26-28 April 2018. Calpe. Alicante, Spain

\section{Analysis of the factor structure of the physical condition of girls 17-19 year-old}

\author{
OLENA YARMAK ${ }^{1}$, OLEKSANDRA BLAGII2, YURII PALICHUK ${ }^{3}$, ANNA HAKMAN ${ }^{3}$, LARISA BALATSKA ${ }^{3}$, \\ OLENA MOROZ ${ }^{3}$, YAROSLAV GALAN ${ }^{3}$ \\ ${ }^{1}$ Bila Tserkva National Agrarian University, Bila-Tserkva, Ukraine \\ ${ }^{2}$ National University of Physical Education and Sports of Ukraine, Kyiv, Ukraine \\ ${ }^{3}$ Yuriy Fedkovych Chernivtsi National University, Chernivtsi, Ukraine
}

\begin{abstract}
The article analyses the factor structure of the physical condition of girls aged 17-19 years. It was determined percentage of each factor and it was established that the general physical condition is determined by a group of four factors: physical development is $41.8 \%$, the functional state of the cardiovascular and respiratory system is $28.4 \%$, physical performance and coordination abilities are $12.4 \%$, physical readiness, in particular speed, speed-strength qualities, agility and flexibility $-2.3 \%$, which together constitute $84.9 \%$ of the explained dispersion. We have found out that the anthropometric status determines the physical condition even after the end of the puberty period. Most factor loading is accounted for the indicators that characterize the total body size: waist girth $(r=-0.975$ at $p<0.01)$; chest girth $(r=-0.966$ at $p<0.01)$; the pelvis girth of $(r=-$ 0.956 for $p<0.01$ ), as well as indicators characterizing the fat component: the sum of the skin-fat folds ( $r=-$ 0.985 at $p<0.01$ ); the suprailiac skinfold, $(r=-0.968$ at $p<0.01)$; the medial (inside) calf fold $(r=-0.950$ at $p<0.01$ ). Based on the analysis of the studied indicators, which form the basis of all four factors, there were obtained results that have the predictive value for the individualization and differentiation of the pedagogical process, as well as the influence assessment of the basic pedagogical tools and methods in the process of physical education. Key words: FACTOR ANALYSIS, PHYSICAL CONDITION, GIRLS.
\end{abstract}

\section{Cite this article as:}

Yarmak, O., Blagii, O., Palichuk, Y., Hakman, A., Balatska, L., Moroz, O., \& Galan, Y. (2018). Analysis of the factor structure of the physical condition of girls 17-19 year-old. Journal of Human Sport and Exercise, 13(2proc), S259-S268. doi:https://doi.org/10.14198/ihse.2018.13.Proc2.11

Corresponding author. Yuriy Fedkovych Chernivtsi National University, Chernivtsi, Ukraine. http://orcid.org/0000-0002-7024$\underline{5690}$

E-mail: y.galan@chnu.edu.ua

Supplementary Issue: Spring Conferences of Sports Science. Costa Blanca Sports Science Week, 26-28 April 2018. Calpe. Alicante, Spain.

JOURNAL OF HUMAN SPORT \& EXERCISE ISSN 1988-5202

(c) Faculty of Education. University of Alicante

doi: 10.14198/jhse.2018.13.Proc2.11 


\section{INTRODUCTION}

The need for constant monitoring of the student's physical condition arises in the context of the natural biological development and improvement of motor functions in difficult conditions of the interaction with the environment. Through the lens of the fundamental provisions of biology, the physiology of activity, the theory of activity, functional systems, adaptation and health, the physical condition is characterized by a combination of indicators reflecting gender characteristics, anthropometric profile, physical fitness, functional state of the muscular and cardio-respiratory system of man (Proios et al., 2015; Andrieieva et al., 2017; Yarmak et al., 2017; Alatzoglou et al., 2017; Bodnar et al., 2018). In the process of individual development, the contribution of these variables to the formation of a person's physical status is changing. The need for such control is felt even more sharply in conditions when the human body is exposed to artificially directed influences in order to realize certain social, biological, physical or other programs for improving its individual functions or the whole system (Yarmak et al., 2017).

Analysis of the modern scientific research proves that motor activity is an integral part of human behaviour, which should ensure the normal functioning of the body systems and health preservation (Romanenko, 2003; Brodáni et al., 2015; Galan et al., 2016; Ivashchenko et al., 2017; Andrieieva et al., 2017; Kozina et al., 2017; Ramírez et al., 2017). Within recent years, the volume of academic workload of students in higher educational establishments in Ukraine has significantly increased. Influence of the innovative educational loads with a high level of the psychoemotional and intellectual load, perception and processing of various information in the conditions of the time deficit, increased requirements for the knowledge volume and quality, intensive use of computer technology in the teaching process negatively affect the functional capabilities of the organism (Tomenko, 2017). In this regard, in the majority of students it is observed a pronounced tension of all regulatory mechanisms and a decrease in the functional capabilities of the organism against the background of the apparent deficit of physical activity (Galan et al., 2017). The success of mastering the curriculum is attributable to many factors, among which the students' health, physical development, physical performance and fitness are rather significant (Yarmak et al., 2017). The period of study at a higher educational establishment is characterized by the formation of typical for an adult person body parameters, in particular: length, the completion of sexual development, the process of ossification of the vertebral column and the completion of somatic formation (Chyzhyk, 2009).

A scientific interest arises to the study of the structure of the physical condition, in particular, the physical development of girls aged 17-19 years, because at this age biological development ends and morphofunctional indicators acquire optimal values (Balamutova, 2011, Sapozhnyk, 2012; Cieślicka, 2012; Kruk, 2013; Bolotin, 2014; Bolotin, 2017; ledynak et al., 2017). At this age, the human body has the greatest stability, economy and reactivity in response to the stress factor of any modality.

\section{MATERIALS AND METHODS}

For the purpose of determining the indicators of physical development of 17-19 year-old girls there were held anthropometric measurements that reflect the level of morphological features: body length (BL), body weight (BW), body mass index (BMI), girth of various body parts, 5 skinfolds, wrist dynamometry. There were used physiological methods of investigation to assess the state of the cardiovascular system of girls: heart rate at rest (HRrest), systolic blood pressure (SBP) and diastolic (DBP), systolic blood volume (Stroke Volume) (SV) and minute blood volume (Cardiac Output) (CO); to assess the state of the respiratory system: vital lung capacity (VC), the Robinson index; physical performance (the Ruffier-Dicson index). To characterize physical fitness, motor tests were used (running $100 \mathrm{~m}$ race, bending forward from the sitting position, flexion and 
extension of arms in front lying support, sit-up from the back-lying position, times for $1 \mathrm{~min}$, rope jumping for $1 \mathrm{~min}$ ); for the evaluation of coordination abilities (a complicated Romberg test) - shuttle running $4 \times 9 \mathrm{~m}$. The implementation of this set of tests covers many aspects of physical fitness.

The results were processed using mathematical statistics. Research work was carried out on the basis of the Bila Tserkva National Agrarian University of the city of Bila Tserkva with girls aged 17-19 years. The study involved 186 girls; all of them are the first year students.

\section{RESULTS}

To determine the structure of the physical condition of girls aged 17-19 years, we conducted a factor analysis, which allowed us to establish and evaluate the percentage contribution of each factor. Thus, the structure of the physical condition of girls is determined by a group of four factors: physical development (41.8\%), the functional state of the cardiovascular and respiratory system $(28.4 \%)$, physical performance and coordination abilities (12.4\%), physical readiness, in particular speed, speed and strength qualities, agility and flexibility $(2.3 \%)$.

The first factor, we identified with the physical development of 17-19 year-old girls, has a factor load of indicators that characterize the total body size: the waist girth $(r=-0.975$ at $p<0.01)$; the chest girth $(r=-0.966$ at $p<0.01)$; the pelvis girth $(r=-0.956$ at $p<0.01)$, BL $(r=0.947$ at $p<0.01)$; BW $(r=-0.929$ at $p<0.01)$, BMl $(r=-$ 0.918 at $p<0.01)$, the shoulder girth $(r=-0.864$ at $p<0.01)$, the thigh girth $(r=-0.822$ at $p<0.01)$. Also the first factor is the factor load of the indicators characterizing the fat component: the sum of the skin and fat folds $(r=-0.985$ at $p<0.01)$, the suprailiac skinfold $(r=-0.968$ at $p<0.01)$, the medial (inside) calf skinfold $(r=-0.950$ at $p<0.01)$, the fold under the shoulder blade - subscapula skinfold $(r=-0.927$ at $p<0.01)$, the biceps skinfold $(r=-0.906$ at $p<0.01)$, the triceps skinfold $(r=-0.862$ at $p<0.01)$. All of them form the basis of the first factor, which has the greatest contribution $-41.8 \%$ to the total dispersion. The average statistical results of the indicators that form the basis of the first factor, presented in Table 1.

Table 1. Indicators of physical condition of the girls aged $17-19$ years $(n=186)$

\begin{tabular}{lccccccc}
\hline \multicolumn{1}{c}{ Indicators } & $\bar{x}$ & $\mathrm{~S}$ & $\mathrm{Me}$ & $25 \%$ & $75 \%$ & Min. & Max. \\
\hline BL, cm & 166.4 & 5.68 & 166.0 & 164.0 & 169.0 & 152.0 & 185.0 \\
$\mathrm{BW}, \mathrm{kg}$ & 61.8 & 13.01 & 59.8 & 53.5 & 66.4 & 42.3 & 99.2 \\
BMI, kg/m² & 22.4 & 4.88 & 21.2 & 19.2 & 24.9 & 15.5 & 33.9 \\
Chest girth, cm & 85.8 & 8.70 & 83.0 & 80.0 & 90.0 & 73.0 & 106.0 \\
Shoulder girth, cm & 27.0 & 3.15 & 27.0 & 25.0 & 29.0 & 20.0 & 34.0 \\
Waist girth, cm & 68.9 & 8.09 & 67.0 & 63.0 & 74.0 & 54.0 & 92.0 \\
Pelvis girth & 95.1 & 7.05 & 94.0 & 90.0 & 100.0 & 82.0 & 117.0 \\
Thigh girth, cm & 52.8 & 6.23 & 53.0 & 50.0 & 56.0 & 30.0 & 68.0 \\
The biceps skinfold, mm & 12.3 & 7.80 & 11.0 & 6.0 & 17.0 & 2.0 & 34.0 \\
The tricep skinfold, mm & 20.3 & 8.37 & 18.0 & 13.0 & 27.0 & 9.0 & 38.0 \\
The subscapula skinfold, mm & 16.3 & 10.18 & 12.0 & 7.0 & 23,0 & 4.0 & 42.0 \\
The suprailiac skinfold, mm & 14.4 & 7.65 & 13.0 & 8.0 & 20.0 & 4.0 & 33.0 \\
The medial calf skinfold, mm & 19.5 & 8.80 & 19.5 & 12.0 & 25.0 & 6.0 & 45.0 \\
Sum of the skin-fat folds, mm & 82.3 & 37.9 & 77.0 & 53.0 & 108.0 & 31.0 & 172.0 \\
\hline
\end{tabular}


In the course of the study of the indicators of the physical development of girls aged 17-19 years, the mean values of the anthropometric indices were obtained, the distribution of which was within the limits of age norms. Analysis of individual BMI parameters in young women allowed to state that $16.1 \%$ of female students had body mass deficit, $64.5 \%$ of girls had normal body weight, $12.9 \%$ of girls had excess body weight, $6.5 \%$ of people had obesity of the first degree. There is a high variability in the parameters of BW, BMl, five skinfat folds and their sum, the variation coefficients are in the range from $V=20.1 \%$ to $V=63.4 \%$, which indicates the heterogeneity of the sample.

The second most important factor determining the structure of the physical condition has factor loadings of indicators characterizing the activity of the cardiovascular and respiratory system: $\mathrm{HR}_{\text {rest }}$ (heart rate at rest) $(r=-0.878$ at $p<0.01)$; VC $(r=0.826$ for $p<0.01)$; the Robinson index $(r=-0.783$ at $p<0.01)$; SBP $(r=0.741$ for $p<0.01)$; $\operatorname{DBP}(r=0.736$ at $p<0.01)$; $\mathrm{SV}(r=0,734$ at $p<0,01) ; \mathrm{CO}(\mathrm{r}=0.722$ for $p<0.01)$. This factor is $28 \%$ of the overall dispersion.

The third most important factor has the factor load of indicators that characterize the physical performance and coordination abilities: the Ruffier index $(r=0.851$ at $p<0.01)$; the sharpened Romberg test $(r=0.793$ at $p<0.01$ ). This factor is $12.4 \%$ of the overall dispersion. The average statistical results that characterize the second and third factors presented in Table 2.

Table 2. Indicators of the functional condition and physical performance of girls aged 17-19 years ( $n=186)$

\begin{tabular}{lccccccc}
\hline \multicolumn{1}{c}{ Indicators } & $\bar{x}$ & $\mathrm{~S}$ & $\mathrm{Me}$ & $25 \%$ & $75 \%$ & Min. & Max. \\
\hline VC, I & 3.5 & 0.59 & 3.5 & 3.1 & 3.9 & 2.0 & 4.6 \\
Robinson index, nominal units & 95.2 & 17.02 & 92.4 & 87.00 & 104.4 & 66.0 & 144.0 \\
HRrest, beats/min-1 & 85.6 & 16.30 & 84.0 & 72.0 & 96.0 & 58.0 & 120.0 \\
SV, ml & 64.6 & 7.93 & 64.0 & 60.57 & 69.8 & 44.5 & 78.7 \\
CO, I.min-1 & 5.5 & 0.45 & 5.3 & 4.72 & 6.3 & 3.9 & 9.0 \\
SBP, mmHg & 111.5 & 8.45 & 110.0 & 110.0 & 120.0 & 100.0 & 130.0 \\
DBP, mmHg & 73.6 & 7.72 & 70.0 & 70.0 & 80.0 & 60.0 & 90.0 \\
Ruffier index, nominal units & 9.7 & 2.90 & 9.0 & 8.0 & 10.4 & 6.4 & 18.0 \\
Sharpened Romberg test, sec & 15.3 & 7.55 & 10.3 & 6.0 & 24.0 & 1.0 & 54.5 \\
\hline
\end{tabular}

In the overwhelming majority of girls aged 17-19 years, the individual results of VC were within the age limit, and only $19.4 \%$ of the results were below the age norms.

The value of the Robinson index serves as an important criterion for the reserve and economization of the cardio-respiratory system function and indicates the aerobic capacity of the body, so in our work we used this indicator to study the respiratory system. Individual indices of the Robinson index in girls aged 17-19 years were of the below average and average level.

The average result of the heart rate at rest is above the age limit, the signs of bradycardia are incidental to $2.7 \%$ of girls, it is also worrying that in $52.7 \%$ of girls aged $17-19$ years the individual results range from 84 beats per min up to 120 beats per min. This fact may indicate a psychoemotional tension.

Systolic BP is one of the most informative functional parameters and it subtly reflects the changes related to the state of its regulatory parts: peripheral vascular resistance, activity of the sympathetic part of the autonomic nervous system, the vasomotor centre tone, the heart force, cardiac output. Diastolic BP depends, 
in turn, on the tone of small and medium vessels and is associated with the activity of parasympathetic innervation and the state of the vascular wall. The value of BP is considered to be a homeostatic index, and therefore its deviation in one direction or another may indicate certain changes in the general functional condition of the organism. In the course of our study, we found out that the signs of hypotension are characteristic of $16.1 \%$ of girls (BP $<110 / 70$ ), and of hypertension - for $21.5 \%$.

The magnitude of $\mathrm{CO}$ is an integral characteristic of the circulation, it contributes to the provision of the metabolic needs and depends on the stroke volume and the heart rate at rest. This indicator was determined by the calculation method, which is used mainly during mass surveys, when, due to the considerable time spent using instrumentation techniques, it is not practical. In spite of the fact that the representativeness is less than in comparison with the experimental methods, the calculation methods as a whole make it possible to obtain the necessary information on the status of the leading hemodynamic parameters and their dynamics, in particular, during physical training and sports. Individual indicators of CO and SV in girls aged 17-19 years were within the age limit.

The average result of girls aged 17-19 years corresponds to the average level of the physical performance. The analysis of individual results allowed to state that girls do not have a high level of physical performance, $17.2 \%$ of girls have a sufficient level, $46.2 \%$ of girls have an average level, $28.0 \%$ of female students have a satisfactory level and $8.6 \%$ of girls have an unsatisfactory level of physical performance.

The average statistical index of the sharpened Romberg test, which characterizes static coordination, was within the normal range in girls aged 17-19 years, although a high variability of $V=49.3 \%$ was observed, indicating a heterogeneity of the sample. It should be noted that $24.2 \%$ of girls had individual results that met an unsatisfactory level.

The fourth factor determining the structure of the physical condition of girls aged 17-19 years is the factor load of the indicators characterizing the speed, speed and strength qualities, agility and flexibility: shuttle run $4 \times 9 \mathrm{~m}(r=0.788$ at $p<0.01)$, running $100 \mathrm{~m}$ race $(r=0.758$ at $p<0.01)$; rope jumping $(r=0.731$ at $p<0.01)$; flexion and extension of arms in front lying support $(r=0.732$ for $p<0.01)$; sit-up from the back-lying position in 1 minute $(r=0.728$ at $p<0.01)$; bending forward from the sitting position $(r=0.716$ at $p<0.01)$. The average statistical results are shown in Table 3.

Table 3. Indicators of the physical fitness of girls aged $17-19$ years $(n=186)$

\begin{tabular}{lccccccc}
\hline \multicolumn{1}{c}{ Indicators } & $\bar{x}$ & $\mathrm{~S}$ & $\mathrm{Me}$ & $25 \%$ & $75 \%$ & Min. & Max. \\
\hline Running 100m race, sec & 17.2 & 1.32 & 17.3 & 16.6 & 18.1 & 15.2 & 21.8 \\
Rope jumping, times/1min & 113.4 & 11.06 & 111.0 & 110.0 & 124.0 & 81.0 & 146.0 \\
Flexion and extension of arms in front lying & 2.9 & 3.10 & 2.0 & 0.0 & 5.0 & 0.0 & 10.0 \\
support, times & & & & & & \\
Sit-up from the back-lying position, times/1min & 29.9 & 8.47 & 32.0 & 27.0 & 33.0 & 11.0 & 48.0 \\
Bending forward from the sitting position, cm & 15.1 & 9.77 & 16.0 & 5.0 & 19.0 & 0.0 & 32.0 \\
Shuttle running 4×9 m., sec & 10.6 & 0.27 & 10.4 & 10.2 & 11.1 & 9.7 & 12.1 \\
\hline
\end{tabular}

Progressive natural development of speed is observed in girls aged 13-14. In the future, the speed of holistic movements in girls of 15 years is very slowly growing and is stabilized until the age of 17 , therefore, with the end of the puberty period, the further biological development of speed practically ceases. In girls the average result in running $100 \mathrm{~m}$ race corresponded to the satisfactory score. 
The level of the strength development determines the degree of manifestation of other physical qualities. As the muscular-skeletal system performs various kinds of work, the strength of the muscles has specific features, especially when the level of physical fitness is being increased. The average statistical results of girls aged 17-19 years in flexion and extension of arms in front lying support and in sit-up from the back-lying position, showed a satisfactory and unsatisfactory score. $25.8 \%$ of the girls failed to perform the motor test in flexion and extension of arms in front lying support, that indicates a low development of the strength qualities, in particular of the forearm flexors and extensors.

Analysing the individual results of the test for flexibility of 17-19-year-old girls, it was found that in $15.1 \%$ they correspond to an unsatisfactory score. Insufficient mobility in the joints limits the level of manifestation of strength, speed and coordination abilities, worsens intramuscular and intermuscular coordination, leads to a decrease in the exercise economy and often causes damage to muscles and ligaments.

The average result in rope jumping corresponds to an excellent mark, only $9.1 \%$ of girls have a satisfactory mark, and $19.9 \%$ have a good mark.

The variety of types of coordination abilities does not allow assessing the level of their development by a unified criterion. Therefore, to determine the level of agility, a test "shuttle run $4 \times 9 \mathrm{~m}$ " was conducted in the physical education of students. The average result in girls 17-19 years old corresponds to the satisfactory mark.

Analysing the indicators characterizing the physical preparedness, in particular speed, speed and strength qualities, agility and flexibility, we observe a high variability in the results of the in flexion and extension of arms in front lying support and in the performance of the flexibility test, the coefficients of variation range from $\mathrm{V}=64.7 \%$ to $\mathrm{V}=106.9 \%$, which indicates the heterogeneity of the sample.

In the course of the study, we carried out correlation interrelations between the indicators characterizing the fat component and form the basis of the first factor with other investigated indicators characterizing physical development, functional state of the cardiovascular and respiratory system, physical performance and fitness. The results of the correlation relationships are presented in Table 4.

Table 4. Correlation of the fat component with indicators of physical condition in girls aged 17-19 years $(n=186)$

\begin{tabular}{lcccccc}
\hline \multicolumn{1}{c}{ Indicators } & 1 & 2 & 3 & 4 & 5 & 6 \\
\hline Age, years & 0.332 & 0.288 & -0.180 & 0.019 & 0.164 & 0.097 \\
$\mathrm{BL}, \mathrm{cm}$ & -0.241 & -0.453 & 0.075 & 0.037 & -0.269 & -0.162 \\
$\mathrm{BW}, \mathrm{kg}$ & 0.738 & 0.843 & 0.847 & 0.847 & 0.816 & 0.879 \\
BMI, kg/m & 0.752 & 0.890 & 0.813 & 0.818 & 0.833 & 0.879 \\
Chest girth, cm & 0.837 & 0.749 & 0.986 & 0.987 & 0.863 & 0.953 \\
Shoulder girth, cm & 0.726 & 0.848 & 0.686 & 0.724 & 0.853 & 0.816 \\
Waist girth, cm & 0.866 & 0.764 & 0.977 & 0.992 & 0.892 & 0.965 \\
Pelvis girth, cm & 0.821 & 0.867 & 0.859 & 0.883 & 0.909 & 0.928 \\
Thigh girth, cm & 0.712 & 0.890 & 0.621 & 0.661 & 0.821 & 0.784 \\
VC, I & 0.328 & 0.295 & 0.290 & 0.339 & 0.287 & 0.324 \\
HR, beats / min-1 & 0.216 & -0.061 & 0.327 & 0.317 & 0.218 & 0.225 \\
SBP, mmHg & 0.282 & 0.196 & 0.506 & 0.511 & 0.312 & 0.399 \\
\hline
\end{tabular}




\begin{tabular}{lcccccc} 
DBP, mmHg & 0.774 & 0.704 & 0.235 & 0.439 & 0.717 & 0.576 \\
Sharpened Romberg test, c & -0.120 & 0.205 & -0.158 & -0.199 & -0.004 & -0.061 \\
Dynamometry right hand, kg & 0.354 & 0.251 & 0.474 & 0.492 & 0.499 & 0.450 \\
Dynamometry left hand, kg & 0.192 & 0.008 & 0.446 & 0.422 & 0,330 & 0.316 \\
The biceps skinfold, mm & 1.000 & 0.893 & 0.779 & 0.894 & 0.970 & 0.953 \\
The triceps skinfold, mm; & 0.893 & 1.000 & 0.670 & 0.761 & 0.899 & 0.885 \\
The subscapula skinfold, mm & 0.779 & 0.670 & 1.000 & 0.972 & 0.818 & 0.919 \\
The suprailiac skinfold, mm & 0.894 & 0.761 & 0.972 & 1.000 & 0.910 & 0.973 \\
The medial calf skinfold, mm & 0.970 & 0.899 & 0.818 & 0.910 & 1.000 & 0.971 \\
Sum of the skin-fat folds, mm & 0.953 & 0.885 & 0.919 & 0.973 & 0.971 & 1.000 \\
Ruffier index, nominal units & -0.419 & -0.359 & -0.423 & -0.397 & -0.427 & -0.433 \\
Bending forward from the sitting position, cm & -0.029 & -0.078 & -0.327 & -0.245 & 0.048 & -0.153 \\
Flexion and extension of arms in front lying & 0.050 & 0.188 & -0.426 & -0.308 & 0.081 & -0.119 \\
support, times & & & & & & \\
Sit-up from the back-lying position, times/1 & -0.563 & -0.232 & -0.672 & -0.713 & -0.614 & -0.604 \\
min & & & & \\
Running 100 m race, sec & 0.534 & 0.285 & 0.295 & 0.408 & 0.359 & 0,385 \\
Shuttle running 4×9 m, sec & 0.310 & 0.250 & 0.337 & 0.313 & 0.384 & 0.217 \\
SV, ml & -0.347 & -0.329 & 0.240 & 0.075 & -0.272 & $-0,097$ \\
CO, I min ${ }^{-1}$ & -0.109 & -0.276 & 0.370 & 0.245 & -0.060 & 0,068 \\
Robinson index, nominal units & 0.346 & 0.043 & 0.533 & 0.527 & 0.359 & 0.399 \\
\hline
\end{tabular}

Note: 1 - the biceps skinfold, $\mathrm{mm}$; 2 - the triceps skinfold, $\mathrm{mm}$; 3 - the subscapula skinfold, $\mathrm{mm}$; 4 - the suprailiac skinfold, $\mathrm{mm} ; 5$ - the medial (inside) calf skinfold, $\mathrm{mm} ; 6$ - sum of the skin-fat folds, $\mathrm{mm}$ Note: $n=186 ; r=0.159$ at $p<0.05 ; r=0.208$ at $p<0.01 ; r=0.263$ at $p<0.001$

During the study of the correlation relationships between the parameters of the fat component and total body size, the functional state of the cardiovascular and respiratory system, indicators of physical work capacity and preparedness, it was established that the correlation coefficients vary within the limits of high reliability.

\section{DISCUSSION}

One of the important elements of the managing system of the process of physical education is the timely monitoring of the physical condition of the student youth. The essence of control and accounting is the identification, comprehension and assessment of real conditions, specific facts, dynamics and results of the pedagogical process. Thanks to the control and accounting, there are accumulated data on the physical condition, technical and tactical preparedness and quantitative achievements of the persons engaged in physical exercises. In addition, it is systematically checked the effectiveness of the means, methods and organizational forms that are applied in the educational process. These data allow to plan more accurately and to modify the educational process, thereby contributing to the improvement of its quality and effectiveness (Beziazychnyi, 2015).

In the process of the individual development the factor load of indicators that characterize the physical condition of a person are changed, changes are affected by lifestyle, motor activity, professional or sports activities. The age of 17-19 years is a critical period of transition from pubertal to postpuberal stage of development, when the corresponding level of physical condition for the following years is built. In the mentioned age period, the components of the physical condition are most easily influenced by external factors, therefore, study of girls aged 17-19 years have prognostic value for assessing the influence of the 
basic pedagogical tools and methods in the process of physical education.

The results of our studies confirm the data (Romanenko, 1999) that physical development takes the leading place among the factors that form the basis of the factor structure of 17-19-year-old girls, and is the main after the puberty period; as well there were confirmed facts about low individual results in strength exercises, in exercises on flexibility, and static coordination (Serhiienko, 2014; Blagii, 2015; Bolotin, 2014; Martins et al., 2017). Our research has acknowledged the high informativeness of the indicators characterizing the fat component for predicting the risk of diseases (Gorshunova, 2008) and the close relationship between the components of the physical condition (Romanenko, 2003). Our studies supplemented the data (Beliak, 2014, Martyniuk, 2016) about the existence of the relationship between the parameters of the girl's body weight and the indicators of physical condition.

\section{CONCLUSIONS}

As a result of factor analysis, we found that the structure of the physical state of girls aged 17-19 is determined by a group of four factors, the leading place belongs to physical development, which has the largest contribution $-41.8 \%$ of the total dispersion. The functional state of the cardiovascular and respiratory system with a factor load of $28.4 \%$ of the total dispersion ranks second for its importance. Physical fitness and coordination abilities, as well as physical readiness, in particular speed, speed, strength, agility and flexibility, form the basis of the third and fourth factors with a factor load of $12.4 \%$ and $2.3 \%$, respectively.

In determining the correlation between the fat component of girls 17-19 years and the parameters characterizing the total body size, the functional state of the cardiovascular and respiratory system, as well as physical fitness and preparedness, it has been established that the correlation coefficients vary within the limits of high credibility $(r=0.208$ at $p<0.01, r=0.263$ at $p<0.001)$ for the sample $n=186$.

\section{REFERENCES}

Alatzoglou, A., Athanailidis, I., Laios, A., \& Derri, V. (2017). The managerial capacity of physical education teachers - principals: The case of Greece. Journal of Human Sport and Exercise, 12(3), 742-752. https://doi.org/10.14198/jhse.2017.123.18

Andrieieva O., Galan Y., Hakman A., \& Holovach I. (2017). Practicing ecological tourism in physical education of primary school age children. Journal of Physical Education and Sport, 17, Supplement issue 1, 7-15. https://doi:10.7752/jpes.2017.s1002

Andrieieva O., Hakman A., Balatska L., Moseychuk Y., Vaskan I. \& Kljus O. (2017). Peculiarities of physical activity regimen of 11-14-year-old children during curricular and extracurricular hours. Journal of Physical Education and Sport, 17(4), 2422-2427. https://doi:10.7752/jpes.2017.04269

Ashanin V., Filenko L., Pasko V., Poltoratskaya A., Tserkovna O. (2017). Informatization on the physical culture of students using the «physical education» computer program. Journal of Physical Education and Sport, 17(3), 1970-1976. https://doi:10.7752/jpes.2017.03195

Balamutova N.M., Brusnik V.V. (2011). Perfection of the methods of pedagogical control of the physical development of students. Physical Education of Students, 2, 6-9.

Beliak Yu.l. (2014). The physical condition of mature women and its dynamics under the influence of health-improving fitness classes. Sports Medicine, 1, 80-86.

Beziazychnyi B.I. (2015). Comprehensive pedagogical control over the physical education of university students. Bulletin of the Chernihiv National Pedagogical University named after T.G. Shevchenko. Pedagogical Sciences. Physical Education, 118 (3), 24-28. 
Blagiy O. L., Yachnyuk M. Yu. (2015). Analysis of indicators of physical condition of student youth. Bulletin of Chernigiv National Taras Shevchenko University. Physical education and sports, 129 (3), 27-32.

Bodnar I, Dukh T, Martyniv O, Hoshovska L. (2018). Can integrative physical education improve physical development of schoolchildren? With a kind of emptiness? Physical Activity Review, 6: 1-7.

Bolotin, A., \& Bakayev, V. (2017). Pedagogical conditions necessary for effective speed-strength training of young football players (15-17 years old). Journal of Human Sport and Exercise, 12(2), 405-413. https://doi:10.14198/jhse.2017.122.17

Bolotin, A.E., Schegolev, V.A., Bakaev, V.V. (2014). Educational technology of use of means of physical culture to adapt students for future professional work. Teoriya i Praktika Fizicheskoy Kultury, (7), 56.

Bolotin, A. E. Bakaev V. V. (2015). Structure and content of the educational technology of managing students' healthy lifestyle. Journal of Physical Education and Sport, 15(3), 362-364.

Brod'áni, J., Paška, L., \& Lipárová, S. (2017). Interaction of physical activity and quality of life of teachers at primary schools and kindergartens. Journal of Human Sport and Exercise, 12(2), 426-434. https://doi:10.14198/jhse.2017.122.19

Chyzhyk V.V., Zaporozhets O.P. (2009). Sports morphology. Textbook for students. Tverdynia, 208.

Cieślicka M., Napierala M., Pilewska W., lermakov S. (2012). Status of morphological and motor skills of girls participating in modern dance classes. Pedagogics, Psychology, Medical-Biological Problems of Physical Training and Sports, 10, 96-104.

Galan Y., Zoriy Y., Briskin Y. \& Pityn M. (2016). Orienteering to optimize the psychophysical wellbeing of young teens (13 to 14-year-old). Journal of Physical Education and Sport, 16(3), 914-920. https://doi:10.7752/jpes.2016.03144

Galan, Y., Soverda I., Zoriy, Y., Briskin, Y., \& Pityn, M. (2017). Designing an effective approach to sport for the integration in higher education institutions (the effects of yoga practice). Journal of Physical Education and Sport, 17 Supplement issue 2, 509-518. https://doi:10.7752/jpes.2017.s2077

Gorshunova N.K., Gorlacheva Ye.I. (2008). The value of body mass index and analysis of the total body composition in revealing the body weight excess in elderly women suffering from hypertension. Clinical Gerontology, 9, 93.

ledynak G., Galamandjuk L., Kyselytsia O., Nakonechnyi I., Hakman A. \& Chopik O. (2017). Special aspects of changes in physical readiness indicators of young men with different somatotypes between 15 and 17 years of age. Journal of Physical Education and Sport, 17(4), 2690-2696. https://doi:10.7752/jpes.2017.04311

Ivashchenko O., Yarmak O., Galan Y., Nakonechnyi I., \& Zoriy Y. (2017). Leadership as a fundamental aspect of the performance of student-athletes in university men's sports teams. Journal of Physical Education and Sport, 17, Supplement issue 2, 472-480. https://doi:10.7752/jpes.2017.s2071

Kolos N.A., Malinskyi I.I., Yaremenko V.V., (2010). Features of morphofunctional development of students. Pedagogy, Psychology and Medico-Biological Problems of Physical Education and Sports, 12, 59-61.

Kozina Z., Prusik K., Görner K., Sobko I., Repko O., Bazilyuk T., Kostiukevych V., Goncharenko V., Galan Y., Goncharenko O., Korol S., Korol S. (2017). Comparative characteristics of psychophysiological indicators in the representatives of cyclic and game sports. Journal of Physical Education and Sport, 17(2), 648-655. https://doi:10.7752/jpes.2017.02097

Kruk R.S., Bergman K. (2013.) The reciprocal relations between morphological processes and reading. Journal of Experimental Child Psychology, 114(1), 10-34. https://doi:10.1016/j.jecp.2012.09.014 
Lazareva O., Aravitska M., Andrieieva O., Galan Y., Dotsyuk L. (2017). Dynamics of physical activity status in patients with grade I-III obesity in response to a physical rehabilitation program. Journal of Physical Education and Sport, 17(3), 1960-1965. https://doi:10.7752/jpes.2017.03193

Martins, J., Torres, B., Cardoso, J., Costa A.M., Honório S. (2015). Influence of sociological aspects on the level of physical activity in physical education students. Journal of Human Sport and Exercise, 10(3), 815-826. https://doi:10.14198//hse.2015.103.07

Martyniuk O. (2016). Indicators of the physical condition of women involved in recreational aerobics. Slobozhansky Scientific and Sports Bulletin, 4, 73-78.

Proios, M., Proios, M.C., Siatras, T., Patmanoglou S. (2015). Students' perceived behaviors at school: A relation between behaviors in physical education lessons and the classroom. Journal of Human Sport and Exercise, 10(3), 113-125. https://doi:10.14198/jhse.2015.101.10

Ramírez, V., Padial, R., Torres, B., Chinchilla, J., Suárez, C., Chinchilla, J., González, S., \& Cepero González, M. (2017). The effect of a "PBL" physical activity program based methodology on the development of values in Spanish Primary Education. Journal of Human Sport and Exercise, 12(4), 1310-1327. https://doi.org/10.14198/jhse.2017.124.17

Romanenko V.A. (1999). Psychophysiological determinants of managing the physical condition of students. Proceedings of the conference of universities of Donetsk Region, 7.

Romanenko V.V., Kuts A.S. (2003). Motor activity and physical condition of students of higher educational institutions. Study Guide, 132.

Romanenko V.A. (2005). Diagnostics of motor abilities. Donetsk National University, 290.

Sánchez-Jover, F., Gómez, A. (2017). Training habits, motivation, quality of life and sport injuries in 12 to 15 years old basketball players. Journal of Human Sport and Exercise, 12(3), 760-774. https://doi.org/10.14198/ihse.2017.123.20

Sapozhnyk 0. (2012). Physical development of female students of the university. Physical Education, Sport and Culture of Health in Modern Society, 20 (4), 330-334.

Serhiienko V. M. (2014). Control and assessment of motor abilities of students in the process of physical training. Monograph. Sumy National University, 125-130.

Tomenko O., Kirichenko L., Skripka I., Kopytina Y., Burla A. (2017). Effect of recreational taekwondo training on musculoskeletal system of primary school age children. Journal of Physical Education and Sport, 17(3), 1095-1100. https://doi:10.7752/jpes.2017.03168

Yarmak O., Galan Y., Hakman A., Dotsyuk L., Oleksandra B., Teslitskyi Y. (2017). The use of modern means of health improving fitness during the process of physical education of student youth. Journal of Physical Education and Sport, 17(3), 1935-1940. https://doi:10.7752/jpes.2017.03189

Yarmak O., Galan Y., Nakonechnyi I., Hakman A., Filak Y., Blahii O. (2017). Screening system of the physical condition of boys aged 15-17 years in the process of physical education. Journal of Physical Education and Sport, 17, Supplement issue 3, 1017-1023. https://doi:10.7752/jpes.2017.s3156

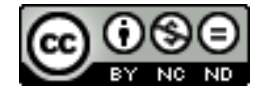

This title is licensed under a Creative Commons Attribution-NonCommercial-NoDerivs 4.0 Unported License. 